IZA DP No. 4357

Labor Market Pooling, Outsourcing and Labor Contracts

Pierre M. Picard

David E. Wildasin

August 2009

Forschungsinstitut zur Zukunft der Arbeit Institute for the Study of Labor 


\title{
Labor Market Pooling, Outsourcing and Labor Contracts
}

\author{
Pierre M. Picard \\ CREA, University of Luxembourg \\ and CORE, Université catholique de Louvain \\ David E. Wildasin \\ University of Kentucky \\ and IZA
}
Discussion Paper No. 4357
August 2009

IZA
P.O. Box 7240
53072 Bonn
Germany

Phone: +49-228-3894-0

Fax: +49-228-3894-180

E-mail: iza@iza.org

\begin{abstract}
Any opinions expressed here are those of the author(s) and not those of IZA. Research published in this series may include views on policy, but the institute itself takes no institutional policy positions.

The Institute for the Study of Labor (IZA) in Bonn is a local and virtual international research center and a place of communication between science, politics and business. IZA is an independent nonprofit organization supported by Deutsche Post Foundation. The center is associated with the University of Bonn and offers a stimulating research environment through its international network, workshops and conferences, data service, project support, research visits and doctoral program. IZA engages in (i) original and internationally competitive research in all fields of labor economics, (ii) development of policy concepts, and (iii) dissemination of research results and concepts to the interested public.
\end{abstract}

IZA Discussion Papers often represent preliminary work and are circulated to encourage discussion. Citation of such a paper should account for its provisional character. A revised version may be available directly from the author. 
IZA Discussion Paper No. 4357

August 2009

\section{ABSTRACT \\ Labor Market Pooling, Outsourcing and Labor Contracts}

Economic regions, such as urban agglomerations, face external demand and price shocks that produce income risk. Workers in large and diversified agglomerations may benefit from reduced wage volatility, while firms may outsource the production of intermediate goods and realize benefits from Chamberlinian externalities. Firms may also protect workers from wage risks through fixed wage contracts. This paper explores the relationships between firms' risks, workers' contracts, and the structure of production in cities.

JEL Classification: R12, R23, J31, J65

Keywords: labor market, labor contracts, Chamberlinian externalities

Corresponding author:

Pierre M. Picard

CREA

University of Luxembourg

$162 \mathrm{a}$, avenue de la Faïencerie

L-1511 Luxembourg

Luxembourg

E-mail: pierre.picard@uni.lu 


\section{Introduction}

Modern explanations for urban agglomeration hinge on departures from "perfect" markets, in the Arrow-Debreu sense, as fundamental reasons why firms and households cluster together. Economies of scale in production are conducive to agglomeration, but result in departures from perfect markets in the form of monopolistic or monopolistically competitive industries. Risk pooling in dense markets may also be conducive to agglomeration when agents are risk averse when it is recognized that markets for risk are incomplete, another type of market imperfection. In this paper, we explore the transmission and pooling of risks in a model of an urban agglomeration characterized by imperfect competition due to economies of scale and by workers' risk aversion. Industries within this agglomeration, which export products to the rest of the economy, face stochastic demands for their products, producing output and income shocks that affect the local economy. We investigate the simultaneous determination of industrial structure, employment relationships, and earnings risk, under varying assumptions about risk aversion and the ability of firms (or workers) to access financial markets within which risks can be traded.

Our analysis is motivated by three stylized facts. First, an emerging literature presents evidence on the existence and the nature of labor market pooling. In a early study, Diamond and Simon (1990) have shown that workers are willing to accept lower wages in locations where many firms locate. More recently, Ellison et al. (2008) offer evidence about the existence of important labor market pooling effects as industries hiring the same type of workers are also more likely to locate near one another. Overman and Puga (2009) highlight in a very precise way the effect of uncertainty on labor market pooling by showing that firms belonging to a same industry and having larger idiosyncratic shocks are more concentrated. Large concentrations of firms therefore smooth firms' idiosyncratic shocks and improve their ability to adapt in good and bad times. Second, the empirical literature presents compelling evidence of the relationship between agglomeration and Chamberlinian input sharing. For instance, Holmes (1999) find that firms are more likely 
to fragment their production and use external inputs (i.e. to disintegrate or outsource production) if they locate close to firms in the same industry. This positive relationship between vertical disintegration and industrial concentration is highly suggestive of the existence of input sharing effects. Similar empirical results are summarized in Rosenthal and Strange (2004). Finally, the empirical literature offers evidence that labor contracts partially shield workers against changes in business and industry risk. For instance, Baker et al. (1994) find that firms' wage policy absorbs most of the shocks arising from idiosyncratic business fluctuations. Beaudry and DiNardo (1991) demonstrate the effect of implicit contracts on wage stability. In many empirical studies, the wage is shown to fluctuate less within the firm than in labor spot markets (e.g. McDonald and Worswick, 1999, for Canada; Devereux and Hart, 2007, for the U.K.). Such stylized facts motivate further investigation of the relationships between business risk, fragmentation, labor markets and labor contracts, which is the objective of the present paper.

This paper discusses a model where outsourcing stems from the fragmentation of firms endowed with a production structure à la Ethier (1982), where uncertainty arises from uncertain prices on external markets or from uncertain productivity, in the spirit of Krugman (1991), Duranton and Puga (2004) and Wildasin (1995) and where firms may be able to insure workers using implicit labor contracts as in Baily (1974), Azariadis (1975) and Rosen (1985). More specifically, as in Ethier (1982), we assume a set of firms in an urban area or economic region operate under conditions of increasing returns to scale. These firms - henceforth called "manufacturing firms", for convenience - produce tradeable goods, using non-traded intermediate goods and services called "components". These intermediate commodities may be produced within the manufacturing firms themselves a vertically-integrated industrial structure. Alternatively, components may be produced by specialized component producers who sell these components to the downstream manufacturing firms. In this "outsourcing" case, manufacturers benefit from input sharing and "Chamberlinian externalities", that is, from the larger diversity of components that 
are produced in a region hosting more component producers (see further discussion in Duranton and Puga, 2000; Fujita and Thisse, 2002, chapter 4). Stochastic demand for traded goods implies that manufacturing outputs, prices, and profits are also random, as are derived demands for intermediate and primary inputs. In particular, external demand shocks may result in stochastic fluctuations in the wages received by risk-averse workers - depending on the nature of labor contracting, and in particular, on whether workers are hired at fixed wages in advance of the realization of external demand shocks or are instead hired (and fired) at wages that depend on these realizations. The equilibrium structure of firms and of employment contracts simultaneously determine the ultimate distribution of income risks among firms and workers within the region.

Note that Krugman (1991) studies the impact of labor market pooling effects on workers' and firms' incentives to co-agglomerate. In contrast, we do not study the location decisions of workers and firms. In the present analysis, labor market pooling arises to the extent that workers and firms endogenously pool their idiosyncratic risks in a common localized labor market. We also study the impact of worker risk aversion and the ability of firms to insure workers against risks. Thus, treating locational decisions as exogenous allows us to investigate in more detail the important relationships between business uncertainty, fragmentation and labor contracting. As will be seen, labor contracting can mitigate the transmission of risk through the local labor market, and thus reduce the importance of labor market pooling. Our study may thus be considered as a preliminary step before investigating the possibility of co-agglomeration of workers and firms in models with richer and more specifications of the labor market than that in Krugman (1991).

The main arguments in the paper can readily be understood by focusing on small business risks. In this case, Chamberlinian input sharing effects drive the choice of the production structure. Under Chamberlinian input sharing, each firm's benefit from outsourcing depends on the outsourcing choice of other manufacturers. Hence, manufacturers can benefit from outsourcing if the location includes many firms and if other manufac- 
turers make the same choice. We thus make a first point by showing that a coordination problem arises and that there can exit multiple equilibria where all manufacturers either integrate or outsource. The manufacturers' production structure in the location can become history dependent and can be locked in a "wrong" configuration. Furthermore, we show that the presence of stronger business risk weakens the benefits from outsourcing and makes it less likely. This is because manufacturers lose some flexibility to adapt their production process to their idiosyncratic demand conditions under outsourcing.

Our second point is to show that the choice of wage contract strongly depends on the prevailing production structure. Integrated manufacturers are shown to be less likely to offer insurance than the many small component producers under perfect financial markets. This is because the small component producers compete more intensively to hire workers (in a monopolistic competition setting) and are therefore more eager to offer insurance to workers. We also show that increases in the amplitude and the correlation of business risks have important impacts on integrated manufacturers' decision to offer labor contracts but that they have a much smaller effect on the component producers' decision. Component producers indeed compete more harshly for workers but they also face more stable demands, the latter being the aggregate of each manufacturer's idiosyncratic demand. Hence, when economic parameters and coordination run in favor of outsourcing, firms offer fixed employment contracts and have fixed sizes; firms then benefit from no risk pooling in the localized labor market. To sum up, our analysis stresses the idea that the importance of labor market pooling effects depends on firms' production structures, which depend on the importance of Chamberlinian input sharing and business risk.

Our analysis begins, in Section 2, with the specification of a basic model of regional production and employment reflecting indivisibilities at the level of export firms and increasing returns in the production of intermediate components as well. Section 3 analyzes this model under the assumption that employers cannot in any way contract with workers in advance of the realization of demand shocks and shows that equilibria can emerge with 
fully integrated manufacturing firms, manufacturing firms that outsource all production of components, or a mix of the two, depending on the number of manufacturing firms in the region. The extent of wage income risk faced by workers in equilibrium also depends on the number of manufacturing firms and on the degree of "diversification" of the region's industrial structure. Section 4 allows for the possibility that firms may be able to absorb some of the income risk otherwise borne by workers by contracting with them ex ante. Such contracts impose costs on firms, in part by limiting their ability to adapt employment to realized demand. Whether such contracts are found in equilibrium depends on trade-offs between these costs and their benefits to risk-averse workers: a range of equilibrium configurations is possible. Section 5 concludes.

Related literature: This paper extends the theoretical literature on the forces underlying labor market pooling effects. First, a number of contributions highlight the importance of labor markets "thickness" in terms of skills, qualification or training (see Helsley and Strange, 1990; Brueckner et al. 2002; or Hamilton and Thisse 2000). Picard and Toulemonde (2004) show that education plays a role in the labor market thickness as higher (professional) skills increases the chance of good job matches between firms and workers in larger regions. Second, some authors explore 'opportunism' issues when firms are able to exploit workers in locations with job opportunities (Combes and Duranton, 2007; Helsley and Strange, 2007). By contrast, Krugman (1991) focuses on the role of uncertainty in labor market pooling. As in our model, firms are uncertain about their costs and reduce wage variability and the risk premium paid to workers when they are located close to one another. However, in contrast to Krugman (1991), we do not study the location decisions but study the effect of risk aversion and labor contracts. Our paper follows the same line as Wildasin (1995) who examines the theoretical implications of integrated or pooled labor markets for the distribution of income risk and for the benefits and costs of tax/transfer policies that protect against such risks. All those contributions ignore the possibility, explored in Section 4 below, that firms may explicitly or implicitly 
insure workers against earnings risk (Baily, 1974; Azariadis, 1975; Rosen, 1985).

Our analysis also extends the large literature on the fragmentation of firms in regional and urban contexts. We put ourselves in the tradition of Stigler (1951), Vernon (1959), and Chinitz (1961) by investigating the link between local industrial organization and agglomeration economies. In contrast to more recent authors such as Egger and Egger (2007), we do not analyze the impact of distance on firms' production structure, nor do we discuss specific urban features such as land use and congestion. We also extend the literature strand initiated by Grossman and Helpman (2002) who study the industry equilibria when firms decide to integrate or to outsource under incomplete contracting and search cost. In this literature strand, Thesmar and Thoenig (2007) discuss the impact of outsourcing decision on wage fluctuations. The key difference between this literature and our paper lies in our focus on (Chamberlinian) input sharing. We indeed study the fragmentation of manufacturers that use a common set of inputs, whereas the above literature investigates the fragmentation of manufacturers that each use a set of components that is specific to each manufacturer. Our study therefore fits better the idea of industrial clusters that share similar inputs as discussed (including with reference to uncertainty) in Vernon (1959). Our analysis finally extends previous research on diversity and specialization. Abdel-Rahman and Fujita (1993) analyze specialized cities (with a single industry) versus diversified cities (with two industries). Duranton and Puga (2001) discuss the migration process of firms from diversified regions to specialized factory towns. Many recent studies of economic geography postulate the existence of regions where final good producers outsource production of intermediate goods to small, diversified, monopolistically competitive firms (see for instance Venables 1996) but take city structure as exogenous in the sense that downstream firms never integrate vertically to incorporate upstream production. As shown in Section 3, vertically integrated industries may but need not always arise when industry structure is determined endogenously. 


\section{The model}

Production structure. We model a region with a predetermined number $M$ of firms, each of which is the sole producer of a commodity that is sold on external markets. ${ }^{1}$ These firms form the "economic base" of the region (Tiebout, 1962). Each firm $j, j=1, \ldots M$, faces a demand for its product given by $Y_{j}=\theta_{j} P_{j}^{-\varepsilon}$, where $P_{j}$ is the price of the commodity, $\varepsilon>1$ is the price elasticity of demand, and $\theta_{j} \in[\underline{\theta}, \bar{\theta}], 0<\underline{\theta}<\bar{\theta}<\infty$, is a firmspecific random variable that reflects demand shocks on external markets. Variations in $\theta_{j}$ may result from fluctuations in incomes, preferences, technologies, and prices of related goods in the rest of the world. With little loss of generality, we assume that $E\left(\theta_{j}\right)=$ $1 \forall j$, and thus the variance and covariance of these shocks are $\operatorname{var}\left[\theta_{j}\right]=E\left(\theta_{j}-1\right)^{2}$ and $\operatorname{cov}\left[\theta_{j}, \theta_{k}\right]_{j \neq k}=E\left(\theta_{j}-1\right)\left(\theta_{k}-1\right)$. In some instances, we assume that these random shocks are i.i.d., but we also allow for them to be correlated, including the possibility that they are perfectly correlated. A low degree of correlation of these shocks can be interpreted as a situation where the region's economic base is highly "diversified", and, as we shall see, this sometimes allows for important pooling of risks; this is not possible when the demand shocks are perfectly correlated. We let $\theta \equiv\left(\theta_{1}, \ldots, \theta_{M}\right)$ denote the vector of random shocks.

Each of the $M$ firms uses various components in the production process; for ease of reference, we henceforth refer to each of these firms as a "manufacturing" firm. As in Ethier (1982), we can think of the production activities of these firms as an "assembly" process in which components are combined to yield a final product, according to a CES production function $Y_{j}=\left[\int_{0}^{N_{j}} x_{j}(i)^{\rho} d i\right]^{1 / \rho}$, where $x_{j}(i)$ is the quantity of component $i$ in the final product $j$; here, $\rho<1$ and the elasticity of substitution between components is $1 /(1-\rho) .^{2}$ Under such a CES production function, each manufacturer benefits from

\footnotetext{
${ }^{1}$ Our model could trivially be extended to incorporate an additional perfectly competitive sector that has a deterministic technology and that uses labor to produce a numéraire commodity, as well as other commodities exported at fixed external prices.

${ }^{2}$ At the cost of notational complexity, it would be possible to incorporate other inputs in the production
} 
economies of scope ("love for variety") that diminish with higher component substitutability. $N_{j}$ represents the total range of components used by firm $j$. The production of each component requires $l_{j}(i)=a+b x_{j}(i)$ units of labor, where $a>0$ and $b>0$ are parameters that represent fixed and variable input requirements, respectively; components are thus produced under conditions of increasing returns to scale. Letting $w_{j}$ denote the wage rate paid by firm $j$, the production of components thus $\operatorname{costs} c_{j}(i)=\left(a+b x_{j}(i)\right) w_{j}$. Throughout, we assume that

$$
\delta \equiv \rho-1+1 / \varepsilon>0
$$

or, stated differently, the elasticity of substitution in production exceeds the elasticity of demand for exported goods, $\varepsilon$. This inequality guarantees that the economies of scope are small enough to lead manufacturers to choose finite production levels. Since the elasticity of demand has already been assumed to be greater than one, this means that $\rho>0$ and, hence, components are substitutes. Note that $\delta<\rho$ and $\delta<\rho / \varepsilon<1 / \varepsilon$.

While the manufacturing firms are the locus of "assembly" activities, they can produce components internally, in which case we refer to them as "integrated" manufacturers, or they may obtain components from specialized local component producers, in which case we refer to them as "outsourcing" manufacturers. The local component producers utilize the same increasing-returns production technologies as are available to the manufacturing firms. Accordingly, the model incorporates no a priori "technological bias" against or in favor of the local component producers. Any advantage that they may enjoy lies in the possibly larger equilibrium scale of component production and larger equilibrium diversity in the types of components produced. When component production is outsourced, we obtain an industrial structure characterized by monopolistic competition in the components sector of the region's economy. One goal of the analysis is to determine endogenously which of these two structures emerges in equilibrium. For the sake of analytical tractability, we assume that outsourcing manufacturers outsource the full production process, but this would not affect the results of the analysis in any important way. 
of components.

Workers. There is a fixed stock $L$ of identical workers in the region, each supplying a single unit of labor. Each worker's utility is a concave function of the wage $w$. For some of the analysis, we assume a constant-elasticity utility function $u(w)=w^{\alpha} / \alpha$ with $\alpha \leq 1$, in which case the (constant) coefficient of relative risk aversion is $1-\alpha$. (Note that $w^{\alpha} / \alpha$ reduces to $\ln (w)$ when $\alpha=0$.) Wages are the only source of income of workers who are assumed, realistically, to be unable to reduce or eliminate wage risk by holding a diversified portfolio of human and nonhuman assets (see Baxter and Jermann, 1997). Risk aversion implies, of course, that workers prefer employment contracts with fixed rather than variable wages.

Labor Markets. We assume that whereas firms have market power in the product and component markets, firms and workers are price and (expected) utility takers in the labor market. This price-taking condition naturally holds when the number of firms is large. When the number of firms is small, we keep this assumption for the sake of consistency and tractability.

We allow for two possible types of employment relationships. In the first, firms hire workers ex post (i.e., subsequent to the realization of demand shocks) in single competitive market at a wage rate of $w$. In the second, firms may contract with workers ex ante to supply their labor at a fixed (non-state-contingent) wage $w^{\prime}$. This first of these assumptions, which is commonplace in the literature of urban and regional economics, prohibits firms from contracting with risk-averse workers in ways that protect the latter from income risk. Its virtue, in the present context, is that it allows us to focus, in Section 3, on the implications of risk for the organization of the production process, independently of risksharing complications. The second assumption, utilized in Section 4, brings risk aversion and risk sharing back into the analysis. Of course, the literature of contract theory offers many alternative models of labor contracting, and future research in urban economics may well explore alternative specifications. Here, for the sake of analytical tractability, 
we will simply assume that contracts are exclusive and non-renegotiable: on the one hand, firms are not allowed to hire additional workers ex post, to fire contracted workers, or to reduce the contracted wage payment; on the other hand, contracted workers are obliged to offer their labor, cannot quit the firm or renegotiate higher wages. In contrast to Schöb and Wildasin (2007), wage contracts not only impose constraints on labor price but also on the size of a contracting firm. Also, in contrast to Duranton and Combes (2006), a firm is not allowed to 'poach' workers from other firms by offering higher ex post wages. ${ }^{3}$ In Section 3, we restrict attention to the case where hiring only occurs ex post; later, we allow for ex ante contracting and for the endogenous determination of contracting form.

Access to Financial Markets. The issue of long-term labor contracting and risk sharing between workers and firms is closely linked to the existence and extent of financial markets through which risks can be diversified. The usual justification for long-term contracting is that firms can bear risks at lower costs than workers because owners of firms, as recipients of nonwage income, can pool risks through portfolio diversification.

Financial markets permitting such diversification may be assumed to operate perfectly and costlessly, and we do examine labor market contracting under this assumption. However, whether all firms have access to financial markets on equal terms is debatable. In particular, smallness is a main feature of monopolistic competition, in which component makers are assumed to engage, and access to capital markets may well be more limited for small, monopolistically competitive firms as compared with large manufacturing firms. In many regions, the intermediate sector often includes small family-run firms funded with limited and unsophisticated capital structures, perhaps built mainly around family assets. Also, it is more costly for investors to monitor smaller firms; the lack of collateral in small businesses usually restricts credit (Audretsch and Elston, 2002). A complete model of endogenous financial structure for monopolistically competitive firms goes well beyond

\footnotetext{
${ }^{3}$ Benefits from larger component variety in cities are not considered in Schöb and Wildasin (2007) and Combes and Duranton (2006).
} 
the scope of the present analysis, but it seems natural at least to consider that small firms may pay a premium, relative to large firms, for access to financial markets.

To capture the differential costs that small firms incur in offering ex ante wage contracts, we assume, in Section 4, that each component producer pays a premium as an additional fixed $\operatorname{cost}(\tau-1) a w>0(\tau \geq 1)$ that is proportional to the production fixed cost $a$ and to the realization of the wage. The total fixed cost then becomes $\tau a w$. The parameter $\tau$ could represent the transactions costs absorbed by small firms when dealing in financial markets, including the extra staffing and other costs that a firm must incur when meeting auditing and control requirements for outside financial counterparts. The special case where $\tau=1$ thus corresponds to the assumption that small firms face perfect capital markets.

\section{$3 \quad$ Risk and Industrial Structure}

In order to focus exclusively on production-side considerations that influence industrial structure in a risky environment, the present section postulates that firms and workers are prohibited from entering into ex ante labor contracts; equivalently, one could assume that workers are risk-neutral, so that such contracts would serve no useful purpose and would not appear in equilibrium.

To understand the incentives to outsource in this setting, we compare the profits of manufacturing firms under integration and under outsourcing.

\subsection{Integrated Manufacturers}

Let $\mathcal{M}$ and $M$ denote, respectively, the set and the number of manufacturing firms and let $\mathcal{M}_{I}$ and $M_{I}$ denote the set and the number of integrated manufacturing firms. Each firm $j \in \mathcal{M}_{I}$ chooses the number of components, hires workers in a perfectly competitive labor market, sets its product price and, finally, supplies its product market. 
By symmetry, firm $j$ produces identical quantities of components: $x_{j}(i) \equiv x_{j}$ for all $i$. The production function then simplifies to $Y_{j}=x_{j} N_{j}^{1 / \rho}$ and the firm's production cost is $\left(a N_{j}+b Y_{j} N_{j}^{\frac{\rho-1}{\rho}}\right) w$, a convex function of $N_{j}$. For any desired level of output $Y_{j}$, the cost-minimizing numbers of each components and of component varieties are given by

$$
x_{j}=\bar{x} \equiv \frac{a}{b} \frac{\rho}{1-\rho} \quad \text { and } \quad N_{j}=\left(Y_{j} / \bar{x}\right)^{\rho} .
$$

Note that changes in output affect only the number of varieties of components, not the amount of each that is used. The optimal labor requirement and the indirect cost function are

$$
l_{j}\left(Y_{j}\right)=c Y_{j}^{\rho} \quad \text { and } \quad c_{j}\left(Y_{j}\right)=c w Y_{j}^{\rho} .
$$

where

$$
c \equiv\left(\frac{b}{\rho}\right)^{\rho}\left(\frac{a}{1-\rho}\right)^{1-\rho}=\frac{b}{\rho} \bar{x}^{1-\rho} .
$$

Cost is a sub-additive function of output. Economies of scope are internalized in the integrated firm so that average costs decrease with output and are larger than marginal cost. Furthermore, both marginal and average costs decrease with output at the (negative) rate $\rho-1$ while inverse demand and marginal revenue functions decrease at the (negative) rate $-1 / \varepsilon$. Under the assumption $\delta \equiv \rho-1+1 / \varepsilon>0$, interior solutions exist and yield maxima for the profit functions $\Pi_{j}=\theta_{j}^{1 / \varepsilon} Y_{j}^{1-1 / \varepsilon}-c w Y_{j}^{\rho}$. Equilibrium output and profit can then written as follows:

$$
\begin{aligned}
& Y_{j}^{\delta}=\theta_{j}^{1 / \varepsilon} \frac{1}{w} \frac{\varepsilon-1}{c \rho \varepsilon} \\
& \Pi_{j}^{I}=\theta_{j} * \theta_{j}^{\frac{1-\rho}{\delta} \frac{\varepsilon-1}{\varepsilon}}\left(w \frac{c \rho \varepsilon}{\varepsilon-1}\right)^{-\left(\frac{\rho}{\delta}-1\right)} \frac{\delta}{\rho}
\end{aligned}
$$

where $\frac{\rho}{\delta}>1$. When wages rise, the equilibrium output $Y_{j}$ decreases. When the firm faces a positive demand shock (i.e., a high value of $\theta_{j}$ ), it increases its output and decreases its product price. Since increases in output reduce the average fixed costs of components, a firm facing a high level of demand or low wages chooses a large number of components. 
In turn, a larger variety of components decreases marginal cost and price. Finally, profit decreases with wages.

Labor demand by all integrated firms is given by

$$
L_{I}\left(w, M_{I}, \Psi_{I}\right)=\sum_{j \in \mathcal{M}_{I}} l_{j}\left(Y_{j}\right)=c\left(\frac{1}{w} \frac{\varepsilon-1}{c \rho \varepsilon}\right)^{\frac{\rho}{\delta}} M_{I}\left(\Psi_{I}\right)^{\frac{\rho}{\delta \varepsilon}}
$$

where

$$
\Psi_{I} \equiv\left[\left(1 / M_{I}\right) \sum_{j \in \mathcal{M}_{I}} \theta_{j}^{\frac{\rho}{\delta \varepsilon}}\right]^{\frac{\delta \varepsilon}{\rho}}
$$

is a measure of the impact of integrated firms' shocks on their total demand for labor. This is an increasing and jointly convex function of $\theta$ because $\delta \varepsilon<\rho$. ceteris paribus, integrated firms hire more workers when market wages $w$ raise, when such firms are numerous (larger $\left.M_{I}\right)$, and when they are hit by a common shock that increases $\Psi_{I}$.

We now turn to the analysis of the manufacturing firms that choose to outsource production to the local component producers.

\subsection{Outsourcing Firms}

Let $\mathcal{M}_{o}$ and $M_{o}$ denote, respectively, the set and number of outsourcing manufacturers. These firms outsource their production of all components to a set of Chamberlinian firms, each producing a single component variety. Outsourcing manufacturers are then just assembly line firms that use components produced by others in the region.

The component sector is subject to Chamberlinian monopolistic competition. Each component maker $i \in[0, N]$ produces a single component and sets a profit-maximizing price $p(i)$, conditional on the realization of all demand shocks for outsourcing manufacturers. Under Chamberlinian monopolistic competition, manufacturers are price takers in the component market. With free entry, component producers' profits fall to zero and the number of component producers reaches its equilibrium value $N$.

The demand for a component is given by the sum of the outsourcing manufacturers'

demands. Each outsourcing firm maximizes its profit $Y_{j} P_{j}-\int_{0}^{N} p(i) x_{j}(i) d i$. Profits are 
concave under the assumption that $\delta>0$. The first-order condition with respect to $x_{j}(i)$ implies that manufacturer $j$ 's demand for component $i$ is given by

$$
\frac{x_{j}(i)}{Y_{j}}=\left[\frac{p(i)}{\mathbf{p}}\right]^{\frac{1}{\rho-1}}
$$

where

$$
\mathbf{p} \equiv\left[\int_{0}^{N} p(i)^{\frac{\rho}{\rho-1}} d i\right]^{\frac{\rho-1}{\rho}}
$$

is the component price index in the region. The manufacturer's cost $\int_{0}^{N} p(i) x_{j}(i) d i$ is then equal to $\mathbf{p} Y_{j}$. So, the outsourcing manufacturer's cost is proportional to the component price index $\mathbf{p}$.

Manufacturing firms' profits can be written as functions of product prices and the component price index as $\Pi_{j}=\left(P_{j}-\mathbf{p}\right) Y_{j}$. Replacing the product demand $Y_{j}$ by $\theta_{j} P_{j}^{-\varepsilon}$, the production and profit of each outsourcing manufacturing firm is computed as

$$
Y_{j}=\theta_{j} \xi \mathbf{p}^{-\varepsilon} \text { and } \Pi_{j}=\frac{1}{\varepsilon-1} \mathbf{p} Y_{j}
$$

where $\xi \equiv(\varepsilon-1)^{\varepsilon} \varepsilon^{-\varepsilon}$. Note that because the profit decreases with the price index $\mathbf{p}$, it increases with a larger variety of local components used in the production process. The outsourcing manufacturer therefore has incentives to purchase all component varieties available in the local market.

Aggregating across manufacturers, component producer $i$ faces an iso-elastic demand function

$$
x(i) \equiv \sum_{j \in \mathcal{M}_{o}} x_{j}(i)=\left[\frac{p(i)}{\mathbf{p}}\right]^{\frac{1}{\rho-1}} \sum_{j \in M_{o}} Y_{j}=\left[\frac{p(i)}{\mathbf{p}}\right]^{\frac{1}{\rho-1}} \mathbf{p}^{-\varepsilon} \xi M_{o} \Psi_{o}
$$

where

$$
\Psi_{o} \equiv \frac{1}{M_{o}} \sum_{j \in \mathcal{M}_{o}} \theta_{j}
$$

is a measure of the average demand shock realized by the outsourcing manufacturers.

The supply of components is derived as follows. Each component producer $i$ manufactures a single variety of component and hires workers in the labor market, where it is price 
taker. It thus maximizes $p(i) x(i)-(a+b x(i)) w$, treating the wage and the price index $\mathbf{p}$ as constants. Because of iso-elastic demand, the optimal price is a constant markup over marginal cost equal to $p(i)=b w / \rho$. Furthermore, free entry requires that profits of component producers are equal to zero. This implies that $x(i)=(a / b)(\rho /(1-\rho))=\bar{x}$. Note that the optimal level of component production turns out to be equal to that chosen by integrated firms. ${ }^{4}$

Applying these results firstly to (6) yields

$$
\mathbf{p}^{\varepsilon \delta}=\frac{w b}{\rho}\left(\frac{\xi M_{o} \Psi_{o}}{\bar{x}}\right)^{\rho-1}
$$

that is, the equilibrium price index of components and therefore the manufacturer's cost are directly related to ex post wages and inversely related to the number of outsourcing manufacturers $M_{o}$.

Using this last expression and (5), we can determine the equilibrium number of component firms:

$$
N_{o}\left(w, M_{o}, \Psi_{o}\right)=\left(\frac{w b}{\rho}\right)^{-\frac{\rho}{\delta}}\left(\frac{M_{o} \Psi_{o}}{\bar{x}}\right)^{\frac{\rho}{\delta \varepsilon}}
$$

The total labor demand by the outsourcing sector is therefore equal to $N_{o}$ times the labor demand of each component producer $(a+b \bar{x})$. Hence this labor demand falls with higher wages $(w)$ and rises with larger numbers of local component producers $\left(M_{o}\right)$ and with positive common shocks on the outsourcing manufacturers (higher $\Psi_{o}$ ).

The outsourcing manufacturer's output and profit are then

$$
\begin{aligned}
& Y_{j}=\theta_{j} \xi^{\frac{1}{\delta \varepsilon}}\left(\frac{w b}{\rho}\right)^{\frac{1}{\delta}}\left(\frac{M_{o} \Psi_{o}}{\bar{x}}\right)^{\frac{\rho-1}{\delta}} \\
& \Pi_{j}^{o}=\theta_{j}\left(\frac{M_{o} \Psi_{o}}{\bar{x}}\right)^{\frac{1-\rho}{\delta} \frac{\varepsilon-1}{\varepsilon}} \frac{\xi^{\frac{\rho}{\delta \varepsilon}}}{\varepsilon-1}\left(\frac{w b}{\rho}\right)^{-\left(\frac{\rho}{\delta}-1\right)}
\end{aligned}
$$

We can make two observations about the outsourcing manufacturers' profits. First, each outsourcing manufacturer benefits from the outsourcing decision of other manufacturers.

\footnotetext{
${ }^{4}$ This is a standard result of CES functions; Dixit and Stiglitz (1977) show, for CES preferences, that equilibrium production is equal to the first best production.
} 
This is because the set of local component producers increases when more manufacturers choose to outsource. Manufacturers then benefit from Chamberlinian externalities through a wider diversity of components. Such a benefit results from the manufacturers' technological preference for input diversity and the deeper specialization of component producers as the same fixed input of each component is shared amongst more than one manufacturer (see Ethier, 1982; Fujita and Thisse, 2002; Puga and Duranton, 2004).

Second, it is interesting to observe the impact of shocks on manufacturers' profits under integration and outsourcing. In general, the profits under integration and outsourcing are nonlinear functions of each firm's shock $\theta_{j}$ because the latter impacts nonlinearly on both wages $w$ and average demand shock $\Psi_{o}$. However, a simple case can be discussed when the region includes many firms with independent shocks and where the set of outsourcing manufacturers is large enough. In that case, $w$ and $\Psi_{o}$ can be considered as constant. The profit of an outsourcing manufacturer $j$ is then linear in its own shock $\theta_{j}$ whereas it is an increasing and convex function of its own shock under integration. ${ }^{5}$ Hence, expected profits do not depend on shock variances under outsourcing whereas they rise with meanpreserving increases of variance under integration. Manufacturers are thus more likely to prefer integration when they face large uncertainties. This is because integration offers better production flexibility: it allows the integrated manufacturer to adapt the spectrum of components contingent on the realization of a production shock whereas an individual manufacturer has no influence on the range of available components under outsourcing (as $N_{o}$ is fixed in expression (8)).

\subsection{Equilibrium Wage Determination}

Equilibrium wages are determined conditional on the realization of demand shocks so as to clear the labor market. A region may include both integrated and outsourcing

\footnotetext{
${ }^{5}$ The impact of convexity on the expected profit of integrated firms is also highlighted in Duranton and Puga (2004), Section 2.4.
} 
manufacturing firms, and these firms compete for labor with component producers. All firms are price takers in the labor market. Labor market clearing requires that

$$
L=L_{I}\left(w, \mathcal{M}_{I}, \Psi_{I}\right)+N_{o}\left(w, \mathcal{M}_{o}, \Psi_{o}\right)(a+b \bar{x})
$$

from which it follows that the equilibrium wage satisfies

$$
\left(\frac{w b}{\rho}\right)^{\frac{\rho}{\delta}}=(a+b \bar{x}) \bar{x}^{\frac{-\rho}{\delta \varepsilon}}\left[\left(\frac{\varepsilon-1}{\varepsilon \rho}\right)^{\frac{\rho}{\delta}} M_{I}\left(\Psi_{I}\right)^{\frac{\rho}{\delta \varepsilon}}+\left(M_{o} \Psi_{o}\right)^{\frac{\rho}{\delta \varepsilon}}\right] L^{-1} .
$$

Thus, the equilibrium wage rises as the number of integrated and outsourcing manufacturers increases and fluctuates according to the aggregate shocks $\left(\Psi_{I}\right.$ and $\left.\Psi_{o}\right)$ of each type of manufacturer.

\subsection{The Deterministic Case}

It is instructive to consider first the special case of the model where all demand uncertainty disappears $\left(\theta_{j}=1 \quad \forall j\right)$. What determines whether manufacturers choose to be integrated or to outsource?

We say that the set of manufacturing firms are in an equilibrium configuration when no firm can profitably switch its own organization of production, given the organizational configuration of all other manufacturers. Because of the assumption that firms act competitively in the labor market, none believe that their choices of integration versus outsourcing have an impact on wages. For any given wage $w$, the ratio of profits under each configuration is equal to

$$
\frac{\Pi_{j}^{o}}{\Pi_{j}^{I}}=\left(\frac{M_{o}}{\widehat{M}}\right)^{\frac{1-\rho}{\delta} \frac{\varepsilon-1}{\varepsilon}} \text { where } \widehat{M} \equiv\left(\delta \varepsilon \rho^{\frac{-\rho}{\delta}}\right)^{\frac{\delta}{1-\rho} \frac{\varepsilon}{\varepsilon-1}}>1
$$

It is apparent that $\widehat{M}$ is a critical value that determines manufacturers' incentives to outsource production. ${ }^{6}$ Low values of $\widehat{M}$ favor outsourcing decisions while high values

\footnotetext{
${ }^{6}$ Comparative statics on $\widehat{M}$ is are difficult to obtain analytically. It can nevertheless be numerically shown that $\widehat{M}>1$ for all admissible values of $\rho \in(0,1)$ and $\varepsilon>1$ such that $\delta>0$ and that $\widehat{M}$ is a decreasing function of $\varepsilon$ and $\rho$.
} 
favor integration. The nature of equilibrium however depends on the value of $\widehat{M}$ and on how the latter compares to the number $M_{o}$ of firms that outsource. When $\widehat{M}>M$, the profits of any one individual manufacturer are increased if it integrates its operations, no matter how other manufacturing firms are organized. It follows that all manufacturing firms make the same integration decision, and that all firms therefore are integrated in equilibrium because $\Pi_{j}^{o} / \Pi_{j}^{I}<1$ for any $M_{o} \leq M$. For $\widehat{M}<M$, the above argument is valid only if there initially is a small number of outsourcing manufacturers in the market $\left(M_{o}<\widehat{M}\right)$. Otherwise, firms have incentives to outsource, and those incentives increase as more firms decide to outsource. The incentives to integrate or outsource are illustrated in Figure 1, where heavy dots indicate equilibrium configurations, showing that there can be multiple equilibria (McLaren, 2000).

\section{Insert Figure 1 here}

To summarize,

Proposition 1 Consider a region of $M$ manufacturing firms with identical deterministic demands. There always exists an equilibrium.

(i) If $\widehat{M}>M$, then all firms choose to integrate.

(ii) If $\widehat{M} \leq M$, then there are two equilibrium configurations: either all manufacturers will be integrated, or all will outsource.

Proof. See Appendix.

Proposition 1 allows us to make the first point of our analysis. Under Chamberlinian input sharing, a coordination problem arises and there can exit multiple equilibria where all manufacturers either integrate or outsource. The manufacturers' production structure in the location can become history dependent and it can be locked in a "wrong" configuration. This result is also consistent with situations in which similar industries appear 
to arrive at different equilibrium configurations. For instance, high-tech firms located along Route 128 in Boston appear to be more highly integrated than their Silicon Valley counterparts, where outsourcing seems to be more prevalent (Saxenian, 1994).

\subsection{The Stochastic Case}

Let us now reintroduce demand uncertainty into the model. We shall assume that firms must choose their organizational form prior to the realization of demand shocks. In this uncertain environment, the ex post wage is also stochastic, as shown in equation (10). We assume throughout that manufacturing firms are risk neutral, that is, they seek to maximize expected profits. The assumption of risk neutrality for these firms rests on a presumption that they have access to financial markets (e.g., equities markets) or are part of larger diversified corporations external to the region, such that their profit risks are effectively shared at no cost.

We say that the set of manufacturing firms are in an equilibrium configuration when no firm can increase its expected profits by switching its own organization of production, given the organizational configuration of all other manufacturers. As before, none believe that their choices of integration versus outsourcing have any impact on wages. The ratio of expected profits under each configuration is given by

$$
\frac{E \Pi_{j}^{o}}{E \Pi_{j}^{I}}=\left(\frac{M_{o}}{\widehat{M}}\right)^{\frac{1-\rho}{\delta} \frac{\varepsilon-1}{\varepsilon}} G_{j}\left(\mathcal{M}_{o}, \mathcal{M}_{I}\right) \quad \text { where } \quad G_{j}\left(\mathcal{M}_{o}, \mathcal{M}_{I}\right)=\frac{E\left(\theta_{j} \Psi_{o}^{\frac{1-\rho}{\delta} \frac{\varepsilon-1}{\varepsilon}} w^{-\left(\frac{\rho}{\delta}-1\right)}\right)}{E\left(\theta_{j} \theta_{j}^{\frac{1-\rho}{\delta} \frac{\varepsilon-1}{\varepsilon}} w^{-\left(\frac{\rho}{\delta}-1\right)}\right)}
$$

As in the deterministic case, the incentive for a firm $j$ to choose integration or outsourcing depends on the number of outsourcing firms $M_{o}$, but now it also depends on the nature of its own demand shocks and the correlation of those shocks with the ex post wage. Again, the incentive to outsource is high when sufficiently many other firms do so $\left(M_{o}\right.$ large).

The impact of shocks is embedded in the function $G_{j}\left(\mathcal{M}_{o}, \mathcal{M}_{I}\right)$, which depends on the sets of firms that outsource and integrate component production. In its general form, 
this function depends on the way manufacturers are partitioned between outsourcing and integrated structures. When there are no shocks, $\theta_{j}=1 \forall j$, this function is equal to 1, and Proposition 1 applies. It also applies when shocks are symmetric and perfectly correlated, since then $\Psi_{o}=\theta_{j}$ and $G_{j}=1 \forall j$. In economic terms, a common shock simultaneously raises the labor demands and the profits of all firms in same proportion, so that the incentives to outsource are unchanged. Thus:

Proposition 2 When manufacturing firms face perfectly correlated shocks, equilibrium configurations exist and are as characterized in Proposition 1.

Somewhat more generally, we may consider ex ante symmetric firms whose demand shocks are identically distributed but are not necessarily perfectly correlated, so that the identity of the firms that outsource or integrate is thus irrelevant. Then the function $G_{j}\left(\mathcal{M}_{o}, \mathcal{M}_{I}\right)$ becomes a function $G\left(M_{o}\right)$ that depends only on the number $M_{o}$ of outsourcing firms. If the function $\left(M_{o} / \widehat{M}\right)^{\frac{1-\rho}{\delta} \frac{\varepsilon-1}{\varepsilon}} G\left(M_{o}\right)$ increases in $M_{o}$, the argument of Proposition 1 applies, but with a new threshold $\widehat{M}_{1}$. How this threshold compares with $\widehat{M}$ is a difficult question. A partial but informative answer can be obtained in the case of small identical risks. Suppose that shocks are distributed with small identical variance $\sigma^{2} \equiv \operatorname{var}\left(\theta_{j}\right)$ and identical correlation $r \equiv \operatorname{cov}\left(\theta_{j}, \theta_{k}\right) / \sigma^{2}$ for all $j \neq k \in \mathcal{M}$. Then, we show in the Appendix that $G\left(M_{o}\right)=1-\sigma^{2}(1-r) \Gamma\left(M_{o}\right)<1$ where $\Gamma\left(M_{o}\right)$ is a positive function of $M_{o}$. Because $\sigma^{2}$ is small, the threshold $\widehat{M}_{1}$ is unique and larger than $\widehat{M}$. It increases with larger shock variance and decreases with higher shock correlation. Consistently with Proposition $2, \widehat{M}_{1}$ is equal to $\widehat{M}$ when shocks are perfectly correlated $r=1$.

Proposition 3 When manufacturing firms face small, identically distributed shocks, equilibrium configurations exist and are characterized as in Proposition 1, except that $\widehat{M}$ must be replaced by $\widehat{M}_{1}\left(\widehat{M}_{1}>\widehat{M}\right)$.

Proof. See Appendix. 
To sum up the discussion so far, we begin in Proposition 1 by noting that multiple equilibria may occur where all firms either integrate or outsource. Propositions 2 and 3 extend this result to the case of uncertainty. Intuitively, business uncertainties reduce the manufacturer's benefits from outsourcing compared to integration. Indeed, the ratio $E \Pi_{j}^{o} / E \Pi_{j}^{I}$ falls as manufacturers face larger uncorrelated shocks. This reflects the above-mentioned advantage of production flexibility in integrated firms. When business uncertainties are higher, manufacturers prefer to keep control over the number and the use of each component. This advantage is even more pronounced when firms face less than perfectly-correlated shocks. As a result, larger business uncertainty increases the likelihood of a locale with integrated manufacturers.

In contrast to Proposition 1, when uncertainty is sufficiently large, the integrated structure can dominate for any number of outsourcing manufacturers in the locale, i.e., $E \Pi_{j}^{o} / E \Pi_{j}^{I}<1$ for all $M_{o}$ and integration of all manufacturers is therefore the equilibrium configuration. Figure 2 gives an example of manufacturers hit by two shock levels $\theta_{j}=$ $\{1-\Delta, 1+\Delta\} \forall j$ that are independent and identically distributed. The lower curves correspond to higher shock amplitudes $\Delta(\Delta=0,0.5,0.9,0.99\}$. When the latter is large enough, we get that $E \Pi_{j}^{o} / E \Pi_{j}^{I}<1$ for all $M_{o}$ so that integration is the only equilibrium, whereas this is not the case for smaller shocks.

\section{Insert Figure 2 here}

When firms' risks are not identically distributed, Chamberlinian externalities dominate for small and large numbers of firms as in the preceding paragraphs. As before, there may exist multiple equilibrium configurations for intermediate numbers of firms. Still, there are two important differences with the previous analysis. First, because firms are not ex ante symmetric, they may take different decisions with respect to their structures. For instance, firms facing high demand uncertainty may always prefer to integrate production because 
this configuration offers better production flexibility. An equilibrium configuration may then include a mix of integrated and outsourcing firms. Second, in the absence of ex ante symmetry, firms get different ex ante profits and may not agree on an equilibrium configuration.

To conclude this section, note that the equilibrium wage is, in general, dependent on the realizations of the demand for the manufacturing firms in the region, which means that workers face wage risk. This is true, of course, when workers are employed by integrated manufacturing firms, since these firms face stochastic demand for their products. It is also true when workers are employed by component-producing firms because demand shocks in external markets are transmitted through the manufacturing firms to the upstream component producers.

Under either type of industrial structure, the magnitude of wage risk depends on the number of manufacturing firms in the region $M$ and on the joint distribution of their demand shocks. In particular, if $M$ is large and the demand shocks are uncorrelated (the case where the $\theta_{j}$ 's are i.i.d.), the variance of the equilibrium wage will be small: the high demand for labor by firms with high levels of output demand will offset the low demand for labor with low demand realizations, so that the total demand for labor is relatively stable. This corresponds to a "diversified" industrial structure for the region. If $M$ is relatively small, however, or if external demand shocks are highly correlated, then demand for labor will vary significantly across states of nature, as will the equilibrium wage; in this case, wage risk will be high. Correlated risks may arise when the region's economic base is highly specialized around just a few types of exported commodities (the automobile industry in Detroit provides one illustration). Since demand on external markets may depend on aggregate economic conditions (the economy-wide business cycle, for instance), the case of correlated risks can also arise when there are many different types of firms in the region's economic base.

The analysis so far has emphasized the role of uncertainty as a determinant of equilib- 
rium industrial structure. The model is one in which labor is pooled within the urban or regional economy and can be reallocated in a state-contingent manner through the labor market. As remarked by Duranton and Puga (2004, Section 2.4), there are "efficiency gains from sharing resources among firms that do not know ex ante how much of these resources they will need". Of course, the pooling of labor means that wage risks are, to some extent, likely to be mitigated, but they need not be completely eliminated. If workers are indifferent to risk, then the fact that wages vary stochastically in response to fluctuations in external demand is, for them, a matter of no consequence. In practice, however, households are risk averse, and wage risk can be very costly to them. This means that workers would value employment relationships that provide some form of insurance against wage fluctuations, a possibility that we have so far precluded by the assumption that all wage determination and employment decisions are made ex post. We now consider the possibility that firms offer labor market contracts prior to the revelation of the state

of nature, which can allow for risks to be shifted and for the cost of risk-bearing to be reduced.

\section{Industrial Structure and Labor Contracts}

In order for workers to be protected from wage risk, they must either be able to obtain insurance that offers state-contingent payments based on wage realizations, or they must be able to contract for wages before the state of nature is known. Because of well-known issues relating to transactions costs and moral hazard, we assume that workers are unable to purchase earnings insurance individually. This means that the only opportunity to obtain protection against wage risk must come from labor contracts. In the spirit of the theory of implicit contracts (Baily, 1974; Gordon, 1974; Azariadis, 1975), when firms are risk neutral, they can provide insurance to workers by offering labor contracts in which wages and employment are fixed ex ante. There are of course many alternative models of labor contracting, but we focus for simplicity on contracts that are exclusive and non- 
renegotiable. Our principal goal is to highlight the way that industrial structure influences equilibrium labor market contracts and the distribution of risk between workers and firms.

The preceding section has emphasized two possible equilibrium configurations where all manufacturers either integrate or outsource. For the sake of exposition we will focus on those two configurations and examine labor contracting by firms in each structure, starting with integrated manufacturers. ${ }^{7}$ Throughout this section, we continue to assume that manufacturing firms have access to financial markets or are otherwise sufficiently diversified that they are indifferent to risk.

\subsection{Labor Contracting By Integrated Manufacturers}

Suppose again that $L$ workers and $M$ manufacturing firms have settled in a region and that all firms have chosen to integrate: $M_{I}=M$ and $M_{o}=0 .{ }^{8}$ Consider an integrated manufacturing firm $j \in \mathcal{M}_{I}$. We first determine the properties of its wage contract and then compare the expected profits of this firm with and without such contracts. Firms can potentially hire workers ex post, in which case firms pay workers the stochastic equilibrium wage as described previously. Alternatively, they can offer ex ante contracts with a fixed wage. Firms and workers are assumed to act as price-takers both in the ex ante and ex post labor markets. This means that no firm can pay a wage lower than the prevailing wage in the ex ante market, $w^{\prime}$, or in the ex post market, $w$. Equilibrium is attained when labor demand is equal to labor supply both ex ante and ex post.

Let $\mathcal{M}_{I}^{\prime}$ and $M_{I}^{\prime}$ denote the set and the number of integrated manufacturers that choose to hire ex ante, and let $L_{I}^{\prime}$ denote the amount of labor that they employ. There are thus $M_{I}-M_{I}^{\prime}$ firms that hire the remaining $L-L_{I}^{\prime}$ workers at a wage rate of $w$, subsequent to the realization of demand shocks. There are three possible types of equilibrium: one in

\footnotetext{
${ }^{7} \mathrm{~A}$ more complete discussion of mixes of outsourcing and integrated structures can be found in Picard and Wildasin (2006).

${ }^{8}$ From Propositions 1 and 3, this is likely to occur when $M$ is sufficiently small or if manufacturers are "locked" into an integrated structure.
} 
which all manufacturers hire in the ex ante market $\left(M_{I}^{\prime}=M_{I}\right)$, one in which none hire in the ex ante market $\left(M_{I}^{\prime}=0\right)$, and one in which some hire in both $\left(0<M_{I}^{\prime}<M_{I}\right)$. If $u\left(w^{\prime}\right)<E u(w), L_{I}^{\prime}$ must be zero because all workers prefer ex post employment, whereas $L_{I}^{\prime}=L$ if $u\left(w^{\prime}\right)>E u(w)$. Thus, to determine which type of equilibrium emerges, we need only to compare the expected profits of integrated firms when $u\left(w^{\prime}\right)=E u(w)$.

Suppose that firm $j$ offers an ex ante contract with a wage $w^{\prime}$ and chooses its production level to maximize $E \Pi_{j}=E\left(\theta_{j}\right)^{1 / \varepsilon} Y_{j}^{1-1 / \varepsilon}-c w^{\prime} Y_{j}^{\rho}$. The expected levels of output and profits for integrated manufacturers will be

$$
\begin{aligned}
Y_{j}^{I^{\prime} \delta} & =\left(E \theta_{j}^{1 / \varepsilon}\right) \frac{1}{w^{\prime}} \frac{\varepsilon-1}{c \rho \varepsilon} \\
\Pi_{j}^{I^{\prime}} & =\left(E \theta_{j}^{1 / \varepsilon}\right)^{\frac{\rho}{\delta}}\left(w^{\prime} \frac{c \rho \varepsilon}{\varepsilon-1}\right)^{-\left(\frac{\rho}{\delta}-1\right)} \frac{\delta}{\rho}
\end{aligned}
$$

where $I^{\prime}$ denotes the levels obtained under ex ante contracting by integrated firms and where $\frac{\rho}{\delta}-1>0$. An integrated firm's labor demand is $l_{j}^{I^{\prime}}=c Y_{j}^{I^{\prime} \rho}$. We now compare the expected profits with and without wage contracts:

$$
\frac{\Pi_{j}^{I^{\prime}}}{E \Pi_{j}^{I}}=\frac{\left(E \theta_{j}^{1 / \varepsilon}\right)^{\frac{\rho}{\delta}}\left(w^{\prime}\right)^{-\left(\frac{\rho}{\delta}-1\right)}}{E\left(\theta_{j}^{\frac{\rho}{\delta \varepsilon}} w^{-\left(\frac{\rho}{\delta}-1\right)}\right)}
$$

where $E \Pi_{j}^{I}$ denotes expected profits for an integrated manufacturer who hires labor in the ex post market.

Assuming constant relative risk aversion, the condition that $u\left(w^{\prime}\right)=E u(w)$ means that $w^{\prime \alpha} / \alpha=E w^{\alpha} / \alpha$, in which case

$$
F_{j}\left(\mathcal{M}_{I} \backslash \mathcal{M}_{I}^{\prime}\right) \equiv \frac{\Pi_{j}^{I^{\prime}}}{E \Pi_{j}^{I}}=\frac{\left(E \theta_{j}^{1 / \varepsilon}\right)^{\frac{\rho}{\delta}}\left(E w^{\alpha}\right)^{-\frac{1}{\alpha}\left(\frac{\rho}{\delta}-1\right)}}{E\left(\theta_{j}^{\frac{\rho}{\delta \varepsilon}} w^{-\left(\frac{\rho}{\delta}-1\right)}\right)} .
$$

Observe from this condition that the incentive to hire ex ante depends on the set of firms that are active in the ex post labor market $\mathcal{M}_{I} \backslash \mathcal{M}_{I}^{\prime}$, but it is independent of the size of the ex post labor market (as measured by $L_{I}^{\prime}$ ). An integrated firm $j$ does not offer 
ex ante contracts iff $F_{j}$ is below one. Thus, an equilibrium occurs when the integrated manufacturers can be partitioned in such a way that $F_{j}\left(\mathcal{M}_{I} \backslash \mathcal{M}_{I}^{\prime}\right)<1$ for all $j \in \mathcal{M}_{I} \backslash \mathcal{M}_{I}^{\prime}$ and $F_{j}\left(\mathcal{M}_{I} \backslash \mathcal{M}_{I}^{\prime}\right) \geq 1$ for all $j \in \mathcal{M}_{I}^{\prime}$. There need not be a unique equilibrium since several partitions of integrated firms may satisfy these equilibrium conditions.

Obviously, at a given configuration $\left(\mathcal{M}_{I} \backslash \mathcal{M}_{I}^{\prime}\right)$, a decrease in workers' risk aversion (larger $\alpha$ ) increases workers' certainty equivalent of wages $\left(E w^{\alpha}\right) / \alpha$ which reduces $F_{j}$ and reduces the profitability of an ex ante contract. When workers are risk-neutral $(\alpha=1)$, the ratio $F_{j}$ is below 1 provided that firm $j$ 's shocks are not correlated too much with wages. Indeed, one can successively write

$$
\begin{aligned}
\frac{\left(E \theta_{j}^{1 / \varepsilon}\right)^{\frac{\rho}{\delta}}(E w)^{-\left(\frac{\rho}{\delta}-1\right)}}{E\left(\theta_{j}^{\frac{\rho}{\delta \varepsilon}} w^{-\left(\frac{\rho}{\delta}-1\right)}\right)} & <\frac{\left(E \theta_{j}^{\frac{\rho}{\varepsilon \delta}}\right)\left(E w^{-\left(\frac{\rho}{\delta}-1\right)}\right)}{E\left(\theta_{j}^{\frac{\rho}{\delta \varepsilon}} w^{-\left(\frac{\rho}{\delta}-1\right)}\right)} \\
& =\frac{1}{E\left[\left(\theta_{j}^{\frac{\rho}{\delta \varepsilon}} / E \theta_{j}^{\frac{\rho}{\varepsilon \delta}}\right) *\left(w^{-\left(\frac{\rho}{\delta}-1\right)} / E w^{-\left(\frac{\rho}{\delta}-1\right)}\right)\right]} \\
& =\frac{1}{1+\operatorname{cov}\left[\left(\theta_{j}^{\frac{\rho}{\delta \varepsilon}} / E \theta_{j}^{\frac{\rho}{\varepsilon \delta}}-1\right),\left(w^{-\left(\frac{\rho}{\delta}-1\right)} / E w^{-\left(\frac{\rho}{\delta}-1\right)}-1\right)\right]}
\end{aligned}
$$

where the inequality in the first line results from Jensen's inequality and the fact that $(z)^{\frac{\rho}{\delta}}$ and $z^{-\left(\frac{\rho}{\delta}-1\right)}, \frac{\rho}{\delta}>1$, are convex functions of $z$, where the second line presents a simple algebraic rearrangement in the denominator and where the last line uses the definition of covariance for variables with means equal to one. When firm $j$ 's shocks are negatively correlated or completely uncorrelated with wages, the covariance in the last line is nonnegative and the ratio is below 1 . In this case, firm $j$ does not offer ex ante contracts: ex ante contracting constrains the ability of the firm to adjust output and employment in response to demand shocks, a cost that is not offset by the willingness of workers to accept a lower wage ex ante.

Some configurations are easy to characterize. First, if the number of manufacturing firms is large and demand shocks are i.i.d., the ex post wage $w$ is almost constant. We get $F_{j}<1$ because $E\left(\theta_{j}^{\frac{\rho}{\delta \varepsilon}}\right)>\left(E \theta_{j}^{1 / \varepsilon}\right)^{\frac{\rho}{\delta}}, \frac{\rho}{\delta}>1$. Hence, integrated firms do not offer ex ante 
contracts in the presence of many other firms with uncorrelated demands. On the one hand, the absence of ex post wage fluctuation makes insurance useless for workers. On the other hand, labor contracting imposes a flexibility cost to the manufacturer because the work force cannot be adapted after the realization of the shock. Therefore, the manufacturer is not inclined to offer such insurance.

Second, if all firms have perfectly correlated demand shocks, so that $\theta_{j}=\theta_{0}$ for all $j$, where $\theta_{0}$ is a common demand shock, then the ex post wage $w$ becomes proportional to $\theta_{0}^{\frac{1}{\varepsilon}}$ and we get that $F_{j}=\left[\frac{1}{\alpha}\left(E \theta_{0}^{\frac{\alpha}{\varepsilon}}\right)^{\frac{1}{\alpha}} / E \theta_{0}^{\frac{1}{\varepsilon}}\right]^{-\left(\frac{\rho}{\delta}-1\right)}>1$ because $\theta_{0}^{\frac{\alpha}{\varepsilon}} / \alpha$ is a more concave function than $\theta_{0}^{\frac{1}{\varepsilon}}$ provided that $\alpha \in(0,1)$. Thus, integrated firms with perfectly correlated demands offer ex ante contracts. The case of a single integrated firm may be viewed as a particular instance of the case of perfectly correlated shocks. Hence, we should expect to see ex ante labor contracting in "factory towns". 9 Note that when workers are risk neutral (i.e., $\alpha=1$ ) and risks are perfectly correlated, firms are indifferent between hiring ex ante or ex post: on the on hand, workers place no value on wage stability, and, on the other hand, firms gain nothing from ex post employment flexibility. To summarize:

Proposition 4 Suppose that the manufacturers in the region choose to integrate production. Then:

(i) in diversified regions with many manufacturers, manufacturers do not contract with workers ex ante;

(ii) if manufacturers have perfectly correlated demand shocks, they do contract with workers ex ante, providing workers with actuarially fair insurance ( $\left.w^{\prime}=E w\right)$;

(iii) when manufacturers face demand shocks that are partially correlated, equilibria are possible in which firms with demand shocks that are highly positively correlated with ex post wages contract for labor ex ante, while firms with demand shocks that are highly

\footnotetext{
${ }^{9}$ Of course the assumption of price-taking behavior is not really justifiable in the case of a sole manufacturing firm, but this result emphasizes the importance of lack of risk diversification as the underlying reason for ex ante labor contracting in this model.
} 
negatively correlated with ex post wages contract for labor ex post.

More intuition can be obtained if we study the case of small demand uncertainty (i.e., variance of $\theta_{j}$ is small compared to its mean value 1 ).

Small risks. For small demand uncertainty (see Appendix), we can compute that $F_{j}\left(\mathcal{M}_{I}\right)<1$ iff

$$
2 \operatorname{cov}\left(\theta_{j}, w / w_{0}\right)<\frac{1}{\varepsilon} \operatorname{var}\left(\theta_{j}\right)+\varepsilon\left[1+(\alpha-1) \frac{\delta}{\rho}\right] \operatorname{var}\left(w / w_{0}\right)
$$

where $w$ is the endogenously-determined ex post wage.

This formula confirms the two previous results: firms do not offer ex ante labor contracts when there are many firms and wages are almost non-stochastic, whereas they do offer such contracts when shocks are highly positively correlated. Furthermore, if workers are sufficiently risk averse, $\alpha$ is very negative and the inequality is not satisfied, which is to say that ex ante contracting dominates in this case.

This formula also shows how ex ante and ex post employment contracts can co-exist: a firm is more likely to hire ex ante if its demand shock has low variance or if it is positively correlated with the ex post wage. Indeed, if it has low variance, the firm does not really need production flexibility and contracting with workers is beneficial. If its shock is positively correlated with ex post wages, the firm expects high product demand when wages are high and low product demand when wages are low; as a consequence, its production and demand for labor is stable and ex ante contracts imposes little cost while offering wage stability to workers.

To make things even clearer, we may substitute for the equilibrium wage from (10) into preceding expression. Then, the hiring choice can be expressed in terms of the demand shocks (see Appendix):

$$
F_{j}\left(\mathcal{M}_{I} \backslash \mathcal{M}_{I}^{\prime}\right)<1 \Longleftrightarrow 2 \operatorname{cov}\left(\theta_{j}, m_{I}\right)<\operatorname{var}\left(\theta_{j}\right)+\left[1+(\alpha-1) \frac{\delta}{\rho}\right] \operatorname{var}\left(m_{I}\right)
$$


where $m_{I}$ is the mean of shocks of integrated firms that do not contract ex ante: $m_{I}=$ $\sum_{k \in \mathcal{M}_{I} \backslash \mathcal{M}_{I}^{\prime}} \theta_{k} /\left(M_{I}-M_{I}^{\prime}\right)$. A first result is that no integrated manufacturer hires ex ante if $\alpha=1$ because $2 \operatorname{cov}\left(\theta_{j}, m_{I}\right) \leq \operatorname{var}\left(\theta_{j}\right)+\operatorname{var}\left(m_{I}\right)$. A second result is that each integrated firm wants to hire ex ante for large risk aversion provided that there remains an integrated firm that does not contract ex ante $\left(m_{I}>0\right)$.

We summarize these results in the following proposition.

Proposition 5 Suppose that the manufacturers in the region choose to integrate production and that risks are small. For low values of risk aversion by workers, no firm hires ex ante. If workers are highly risk-averse, all firms but one hire ex ante. For intermediate values of risk aversion, some firms may hire ex ante while others hire ex post.

\subsection{Labor Contracting Under Outsourcing}

Let us now consider the nature of labor contracting when all manufacturing firms outsource the provision of components $\left(M_{o}=M\right) .{ }^{10}$ The makers of components are assumed to be free to enter both before the realization of demand shocks and subsequent to their realization. In the latter case, entry occurs until ex post profits are zero. In the former case, entry prior to the realization of the shocks occurs until expected profits are zero.

As before, firms can hire workers ex post, paying them the stochastic equilibrium ex post wage, or can hire them ex ante, offering a fixed wage. Competition in both markets means that all firms take as given the market-determined wages, $w$ for the $e x$ post stochastic wage and $w^{\prime}$ for the ex ante fixed wage. Equilibrium is attained when labor demand is equal to labor supply both ex ante and ex post.

Again, there are three possible types of equilibrium: one in which all workers are hired ex ante, one in which all are hired ex post, and one in which some are hired in

\footnotetext{
${ }^{10}$ From Propositions 1 and 3, this is likely to occur when $M$ is sufficiently large and manufacturers are locked into an outsourcing equilibrium.
} 
both periods. Let $N^{\prime}$ denote the number of component producers that hire in the ex ante market; $N-N^{\prime}$ is then the number of component firms hiring workers ex post.

In the ex ante stage, a component producer $i$ chooses its production $x^{\prime}(i)$ to maximize its ex ante profit given the contractual wage $w^{\prime}$. That is, the component producer maximizes $\pi^{\prime}(i)=E\left[p^{\prime}(i) x^{\prime}(i)-w^{\prime}\left(\tau a+b x^{\prime}(i)\right)\right]$ where $\tau \geq 1$ is the transaction cost (or risk premium) that small enterprises incur when they make ex ante financial commitments. By (5),

$$
p^{\prime}(i)=x^{\prime}(i)^{\rho-1} \mathbf{p}^{\varepsilon \delta}\left(M_{o} \Psi_{o}\right)^{1-\rho}
$$

The optimal output and profit are computed as

$$
x^{\prime}(i)=M_{o}\left[\frac{\rho E\left(\Psi_{o}^{1-\rho} \mathbf{p}^{\varepsilon \delta}\right)}{b w^{\prime}}\right]^{\frac{1}{1-\rho}}
$$

and

$$
\pi^{\prime}(i)=\frac{a w^{\prime}}{\bar{x}}\left[x^{\prime}(i)-\tau \bar{x}\right]
$$

Component producers enter in the ex ante stage as long as they make non-negative profits, which is equivalent to the condition: $x^{\prime}(i)>\tau \bar{x}$. This condition implies that wage offers remain low enough for entry to occur. Therefore, component producers enter ex ante if they are able to offer a wage $w^{\prime}$ such that

$$
E u(w) \leq u\left(w^{\prime}\right) \leq u\left[\frac{\rho}{b}\left(\frac{M_{o}}{\tau \bar{x}}\right)^{1-\rho} E\left(\Psi_{o}^{1-\rho} \mathbf{p}^{\varepsilon \delta}\right)\right] .
$$

The first inequality requires that the ex ante wage offers workers a level of utility as great as the expected utility that they obtain in the ex post market; the second inequality requires that the ex ante wage is low enough for the component makers to break even. (The expression after the second inequality is obtained by solving for $w^{\prime}$ from (15) under the break-even condition $x^{\prime}=\tau \bar{x}$.) If the first inequality is not satisfied, workers are unwilling to contract ex ante, and if the second inequality is not satisfied, then no firms wish to enter ex ante; in either case, $N^{\prime}=0$. 
In this analysis, the ex post labor market includes only component producers. ${ }^{11}$ If component producers hire workers ex post, free entry insures that the price index for components will satisfy (7). Given this price index, the ex ante production of component producers will be

$$
x^{\prime}(i)=\left[\frac{E w}{w^{\prime}(i)}\right]^{\frac{1}{1-\rho}} \bar{x} .
$$

Therefore, the profitability condition $x^{\prime}(i)>\bar{x}$ is equivalent to $w^{\prime} \leq \tau^{\rho-1} E w$ and it follows that labor will be hired in the ex ante labor market if

$$
E u(w) \leq u\left(w^{\prime}\right) \leq u\left(\tau^{\rho-1} E w\right)
$$

We analyze the case of perfect and imperfect financial markets in the region.

Perfect Financial Markets. When $\tau=1$, the above condition is always satisfied. When financial markets are perfect, free entry implies that the right-hand relationship is satisfied as an equality (i.e., $\left.w^{\prime}=E w\right)$ while the fact that $u(E w)>E u(w)$ implies that no workers are willing to be hired ex post. At the same time, since $w^{\prime}=E w, x^{\prime}(i)=\bar{x}$.

We therefore get the following proposition.

Proposition 6 Suppose that the manufacturers in the region choose to outsource production and that financial markets are perfect $(\tau=1)$. Then, component producers always contract with workers ex ante. The ex ante level of output of each component is equal to its ex post level. Workers receive actuarially fair insurance against shocks $\left(w^{\prime}=E w\right)$ and they have strictly higher utility than if component firms were not able to offer ex ante contracts.

When $\tau=1$, ex ante entry does not have any impact on ex post wages because the labor resources required by firms contracting ex ante, $a+b x^{\prime}(i)$, are exactly equal to the

\footnotetext{
${ }^{11}$ See Picard and Wildasin (2006) for the analysis of a labor market where integrated and outsourcing manufacturers co-exist.
} 
labor demand of the same firms if they hired workers ex post, $a+b \bar{x}$. As a result, the expected utility of workers increases only through better insurance.

Proposition 6 significantly contrasts with Proposition 4 because component suppliers always offer ex ante labor contracts provided that they have access to perfect financial markets. In particular, when regions are diversified with many manufacturers, workers do not demand much insurance because of the mild fluctuations of their ex post wages. In this case, components suppliers are indifferent between offering ex ante contracts or not, whereas integrated manufacturers definitely find it unprofitable because they lose the flexibility to adapt their production to shocks. Component producers have no need for such production flexibility because the component demand is also very stable in a diversified region. This explains why component producers are more likely to offer insurance to workers. This analysis thus shows how labor contracts, and the cost of risk bearing, may vary under different industrial structures.

Of course, this result does not take into account the fact that financing may be more difficult in small firms like component producers. If the transaction cost (or risk premium) $\tau$ is high they may not find any financial arrangements to support their business and labor contracting policies. This is the topic of the next short discussion.

Imperfect Financial Markets. When financial markets are not perfect, each component producer $i$ must produce no less than $\tau \bar{x}$ to break even. Because production of components is inversely related to the ex ante wage $w^{\prime}$, component producers tend to offer lower wages as $\tau$ rises. However, when ex ante wages are too small, workers are unwilling to contract ex ante.

For the sake of exposition, and consistently with Section 4.1, we focus on the assumption of constant relative risk aversion $\left(u(w)=w^{\alpha} / \alpha\right)$. Define a threshold value of $\tau, \tau_{0}$, such that

$$
\tau_{0}^{1-\rho}=\frac{E \Psi_{o}^{1 / \varepsilon}}{\left[E \Psi_{o}^{\alpha / \varepsilon}\right]^{1 / \alpha}}
$$


We then get the following proposition:

Proposition 7 Suppose that the manufacturers in the region choose to outsource production and that financial markets are imperfect $(\tau>1)$. Then all component firms hire workers ex ante if $\tau<\tau_{0}$ and none of them hire workers ex ante otherwise. When workers are hired ex ante, they not only avoid wage risk, they obtain higher expected wages.

Proof. See Picard and Wildasin (2006).

Thus, the state of the financial market is a crucial determinant of the labor contract structure offered by small component producers. On the one hand, these firms are more likely to offer insurance to their workers because they suffer from smaller demand fluctuations and therefore place a lower value on the flexibility provided by ex post labor contracting. On the other hand, their ability to provide ex ante labor contracts depends on whether they can readily fund their business and labor obligations in the regional financial market.

\section{Conclusion}

This paper has explored the interactions between labor market pooling, the structure of production, labor market contracting. It uses a model in which manufacturing firms produce outputs for external markets by assembling components that are locally-produced. Manufacturers choose either to produce these intermediate components internally or to purchase them from monopolistically-competitive local firms. External demands are stochastic and the local economy therefore is subject to stochastic shocks. Depending on whether local production is carried out through integrated manufacturing firms or through outsourcing to local producers, and depending on the nature of labor market contracts, these external demand shocks are absorbed by firms and workers in the local economy. We have examined several related matters: (a) How is production organized, in equilibrium, and how does this depend on the joint distribution of external demand 
shocks - their magnitudes and correlation? (b) What are the implications of demand shocks for the allocation of labor and for the riskiness of wages? (c) When workers are risk averse, do firms have incentives to offer labor contracts that provide workers with employment and wage security? Do these incentives depend on the organization of local production?

We have examined these questions within an admittedly stylized model, but one that allows for indivisibilities in production, endogenous industry organizational structure, risk, and endogenous labor contracting. Within this rich structure, many equilibrium outcomes are possible. Several important results emerge.

First, an integrated firm structure emerges in equilibrium in a region with a small number of manufacturing firms. With larger numbers of firms, however, outsourcing of component production to specialized local producers can occur. Due to underlying indivisibilities in production technologies, however, whether manufacturing firms choose to outsource depends positively on the choices of other manufacturers, giving rise to multiple equilibria. For a given set of economic parameters, there may be equilibria with where all manufacturers are integrated, or, alternatively, where all choose to outsource. We do not explicitly study the progressive development of a region over time, but the analysis suggests that a region that develops by hosting successive manufacturing firms may begin with, and remain locked into, a possibly inefficient integrated industrial structure. When manufacturing firms face greater demand shocks, and when these shocks are less strongly correlated, the incentive to outsource is weakened.

The nature of equilibrium labor contracts depends on the industrial structure in a region. We assume that integrated manufacturers have access to internal or global financial markets that allow them to insure against both demand risks and wage risks. Integrated manufacturers may therefore choose to offer insurance to risk-averse workers through fixed wage contracts. The benefit to workers from such insurance is modest in large regions with highly diversified risks, however. It turns out that integrated manufacturers tend 
not to contract ex ante with workers in large regions hosting many manufacturers with uncorrelated shocks, but they may offer ex ante contracts when shocks are highly correlated. On the other hand, manufacturers facing external demands that are sufficiently correlated with the ex post wage elect to hire workers ex ante, whereas manufacturers with demand shocks that are sufficiently negatively correlated with ex post wages do not hire ex ante. Integrated firms are more likely to offer wage contracts when workers are more risk averse.

When manufacturing firms outsource, labor contracts may, but need not, be offered by small component producers. An employer's ability to insure workers depends on its access to financial markets, and we assume that small component producers may face higher financial transaction costs than large manufacturing firms. Competition for risk-averse workers can lead small component producers to offer wage and employment protections to workers, but they will not do so if financial transactions costs are too high.

More precisely, there is a threshold value of transactions costs, above which component producers only contract with workers after stochastic shocks are realized and workers therefore face risky wages. On the other hand, if component producers can access financial markets at sufficiently low cost, they will offer fixed-wage contracts to workers, irrespective of the structure of risks in the region. This result is in contrast to the situation in large diversified regions with integrated manufacturing firms, as these firms find it too costly to offer job security to workers who, at the same time, face only limited wage risk in the ex post labor market.

In conclusion, let us note that in different historical periods and across the world, regions differ in the numbers and types of goods that are traded with the rest of the economy, in the size and correlation of external risks that they face, in their patterns of growth and development, and in the degree to which financial markets enable firms to relieve workers of risk through ex ante contracting. The foregoing analysis has shown that such factors can be expected to influence the equilibrium characteristics of regional 
economies, so that various regions, at various times, may or may not exhibit a highly integrated structure of production, a high degree of wage risk, or durable labor contracts.

One key simplifying assumption that has been maintained throughout is that the locational choices of firms and workers has been taken as exogenous. The analysis shows that the importance of labor market pooling effects depends on firms' production structures, which in turn depend on the importance of Chamberlinian input sharing and business risk. In fact, when the equilibrium production structure is characterized by outsourcing, firms with good access to financial markets offer fixed employment contracts and have fixed production plans. They then do not benefit from pooling risk in the localized labor market. The incentives to co-agglomerate in the same region are therefore mitigated, in contrast to Krugman (1991). In an economy with interregionally-mobile firms and workers, it seems clear that the attractiveness of different regions, and thus the degree of agglomeration in the entire economy, is affected by the equilibrium configurations of each of the regional economies. The analysis of the equilibrium of a system of regions, each with possibly different (and simultaneously determined) internal equilibria, is a topic that warrants additional investigation. 


\section{References}

Rahman, A. H., Fujita, M., 1993. Specialization and Diversification in a System of Cities, Journal of Urban Economics 33, 189-222.

Audretsch, D., Elston, J., 2002. Does firm size matter? Evidence on the impacts of liquidity constraints on firm investment behavior in Germany, International Journal of Industrial Organization 20, 1-17.

Azariadis, C, 1975. Implicit Contracts and Underemployment Equilibria, Journal of Political Economy 83(6), 1183-1202.

Baily, M., 1974. Wages and Unemployment under Uncertain Demand, Review of Economic Studies 41, 37-50.

Baxter, M., Jermann, U. J., 1997. The international diversification puzzle is worse than you think, American Economic Review 87(1), 170-180.

Brueckner, J. K.,Thisse, J.-F., Zenou , Y., 2002. Local Labor Markets, Job Matching and Urban Location, International Economic Review 43, 155-171.

Chinitz, B., 1961. Contrasts in agglomeration: New York and Pittsburg, American Economic Review 1961, 279-89.

Combes, P.-P., Duranton, G., 2006. Labor Pooling, Labor Poaching and Spatial Clustering, Regional Science and Urban Economics 36(1), 1-28.

Diamond, Ch., Simon, C. 1990. Industrial Specialization and the Returns to Labor, Journal of Labor Economics 8, 175-201.

Duranton, G., Puga, D., 2000. Diversity and specialization in cities: why, where and when does it matter, Urban Studies 37, 533-55.

Duranton, G., Puga, D., 2001. Nursery cities: Urban diversity, process innovation, and the life cycle of products, American Economic Review 91(5), 1454-1477. 
Duranton, G., Puga, D., 2004. Micro-foundations of Urban Agglomeration Economies, in: Henderson, V., Thisse, J.-F. (Eds.), Handbook of Urban and Regional Economics, vol. 4, 2063-2118.

Egger, H., Egger P., 2007. Outsourcing and trade in a spatial world, Journal of Urban Economics 62(3), 441-470.

Ethier, W., 1982. National and International returns to scale in the modern theory of International trade, American Economic Review 72, 389-405

Fujita M., Thisse J.-F., 2002. Economics of Agglomeration: Cities, Industrial Location and Regional Growth, Cambridge University Press.

Glenn, E., Glaeser, E., Kerr, W., 2007. What Causes Industry Agglomeration? Evidence from Coagglomeration Patterns, NBER Working Papers 13068, National Bureau of Economic Research, Inc.

Grossman, G. M, Helpman, E. , 2002. Integration versus outsourcing in industry equilibrium, Quarterly Journal of Economics 117(1), 85-120.

Hamilton J., Thisse, J.F., Zenou, Y., 2000. Wage Competition with Heterogeneous Workers and Firms, Journal of Labor Economics 18, 453-472.

Helsley, R.W., Strange, W.C., 1990. Matching and Agglomeration Economies in a System of Cities, Regional Science and Urban Economics 20, 189-212.

Helsley R.W., Strange, W.C., 2007. Agglomeration, Opportunism and the Organization of Production, Journal of Urban Economics 62 (1), 55-75.

Holmes, T., 1999. Localization of industry and vertical disintegration, Review of Economics and Statistics 81(2), 314-325.

Krugman, P.R., 1991. Geography and Trade, MIT Press, Cambridge, MA.

McLaren, J., 2000. Globalization and Vertical Structure, American Economic Review $90(5), 1239-54$. 
Overman, H.G. and Puga, D., 2009. Labour Pooling as a Source of Agglomeration: An Empirical Investigation.CEPR discussion paper 7174.

Picard, P.M., Toulemonde, E., 2004. Endogenous Qualifications and Firms' Agglomeration, Journal of Urban Economics 55(3), 458-477.

Picard, P.M., Wildasin, D.E., 2006. Labor Market Pooling, Outsourcing, and Contracts in Chamberlinian Regions, Core Discussion Paper No. 2006-60.

Rosen, S., 1985. Implicit Contracts: A Survey, Journal of Economic Literature 23, 11441175.

Rosenthal, S., Strange, W. 2004. Evidence on the Nature and Sources of Agglomeration Economies: in Henderson, V., Thisse J.-F. (Eds.), Handbook of Urban and Regional Economics, vol 4, 2119-2172.

Saxenian, A., 1994. Regional Advantage: Culture and Competition in Silicon Valley and Route 128, Cambridge, Harvard University Press.

Schöb, R., Wildasin, D.E., 2007. Economic Integration and Labor Market Institutions: Worker Mobility, Earnings Risk, and Contract Structure, Regional Science and Urban Economics 37(2), 141-164.

Stigler, G.J., 1951. The Division of Labor Is Limited by the Extent of the Market, Journal of Political Economy, 59(3), 185-193.

Thesmar, D., Thoenig, M. 2007. From Flexibility to Insecurity: How Vertical Separation Amplifies Firm-level Uncertainty, Journal of the European Economic Association 5(6), 1161-1202.

Tiebout, C. M., 1962. Community Economic Base Study, New York: Committee for Economic Development.

Venables, A.J., 1996. Equilibrium Locations of Vertically Linked Industries, International Economic Review 37, 341-359.

Vernon, R., 1959. The Changing Economic Function of the Central City, New York: 
Committee for Economic Development.

Wildasin, D.E., 1995. Factor Mobility, Risk, and Redistribution in the Welfare State, Scandinavian Journal of Economics 97, 527-546.

\section{Appendix}

\subsection{Proof of Proposition 1}

Proof. Let us write profits as function of the number of outsourcing manufacturing firms: $\Pi_{j}^{o}\left(M_{o}\right)$ and $\Pi_{j}^{I}\left(M_{o}\right)$. In equilibrium, a manufacturer integrates if it gets a higher profit by doing so $\left(\Pi_{j}^{I}\left(M_{o}-1\right) \geq \Pi_{j}^{o}\left(M_{o}\right)\right)$ whereas it outsources if it gets a lower profit $\left(\Pi_{j}^{o}\left(M_{o}+1\right)>\Pi_{j}^{I}\left(M_{o}\right)\right)$. Given that manufacturers are price takers in the labor market they consider the wage as fixed. So, by (3) and (9), we can write that $\Pi_{j}^{o}\left(M_{o}\right) \leq \Pi_{j}^{I}\left(M_{o}-1\right)$ if $M_{o} \leq \widehat{M}$. This means that, in a region with $M_{o}$ outsourcing manufacturers, any outsourcing firm wants to integrate and operate in the same region with $M_{o}-1$ outsourcing firms. Conversely, we have that $\Pi_{j}^{o}\left(M_{o}+1\right)>\Pi_{j}^{I}\left(M_{o}\right)$ if $M_{o}+1>\widehat{M}$. So, in a region with $M_{o}$ outsourcing manufacturers, an integrated firm wants to outsource and become the $M_{o}+1^{\text {th }}$ outsourcing firm in this region. Then, (i) if $M<\widehat{M}$, any outsourcing manufacturer chooses to integrate because $M_{o}<\widehat{M}$ for any $M_{o}=1, \ldots, M$, which implies that $\Pi_{j}^{o}\left(M_{o}\right) \leq \Pi_{j}^{I}\left(M_{o}-1\right)$. (ii) Consider now the case where $M \geq \widehat{M}$. Then, on the one hand, for any $1 \leq M_{o} \leq \widehat{M}$, we have that $\Pi_{j}^{o}\left(M_{o}\right) \leq \Pi_{j}^{I}\left(M_{o}-1\right)$ so that any outsourcing manufacturer wants to switch to integration. This triggers an unraveling process with smaller and smaller $M_{o}$. The equilibrium is at $M_{o}=0$ : all firms integrate. On the other hand, for any $\widehat{M}<M_{o}+1 \leq M$, we have that $\Pi_{j}^{o}\left(M_{o}+1\right)>\Pi_{j}^{I}\left(M_{o}\right)$ so that any integrated manufacturer wants to switch to outsourcing. This triggers an unraveling process with larger and larger $M_{o}$. The equilibrium is at $M_{o}=M$ : all firms outsource. Note that the configuration $M_{o} \in(\widehat{M}-1, \widehat{M})$ can unravel in both direction; it is anyway not an equilibrium. 


\subsection{Proof of Proposition 3}

We need to compute the approximation of

$$
G\left(M_{o}\right)=\frac{E\left(\theta_{j} \Psi_{o}^{\frac{1-\rho}{\delta} \frac{\varepsilon-1}{\varepsilon}} w^{-\left(\frac{\rho}{\delta}-1\right)}\right)}{E\left(\theta_{j} \theta_{j}^{\frac{1-\rho}{\delta} \frac{\varepsilon-1}{\varepsilon}} w^{-\left(\frac{\rho}{\delta}-1\right)}\right)}
$$

when shocks are distributed with small enough identical variance $\sigma^{2} \equiv \operatorname{var}\left(\theta_{j}\right)$ and identical correlation $r \equiv \operatorname{cov}\left(\theta_{j}, \theta_{k}\right) / \sigma^{2}$ for all $j \neq k \in \mathcal{M}$. Let $F=\theta_{j} \Psi_{o}^{\frac{1-\rho}{\delta} \frac{\varepsilon-1}{\varepsilon}}\left(w / w_{0}\right)^{-\left(\frac{\rho}{\delta}-1\right)}$ and $H=\theta_{j} \theta_{j}^{\frac{1-\rho}{\delta} \frac{\varepsilon-1}{\varepsilon}}\left(w / w_{0}\right)^{-\left(\frac{\rho}{\delta}-1\right)}$ where $w_{0}$ is the wage $w$ under no risk $\left(\theta_{k}=1\right)$. We get

$$
E(F) \simeq 1+\sum_{k \in \mathcal{M}} \frac{\partial F}{\partial \theta_{k}} E\left(\theta_{k}-1\right)+\frac{1}{2} \sum_{k \in \mathcal{M}} \sum_{l \in \mathcal{M}} \frac{\partial^{2} F}{\partial \theta_{k} \partial \theta_{l}} E\left[\left(\theta_{k}-1\right)\left(\theta_{l}-1\right)\right]
$$

where the second term vanishes because $E\left(\theta_{k}-1\right)=0$ for all $k$ and where $E\left[\left(\theta_{k}-1\right)\left(\theta_{l}-1\right)\right]=$ $\operatorname{cov}\left[\theta_{k}, \theta_{l}\right]$ is of the same order as $\sigma^{2}$. A similar expression holds for $E(H)$. Hence,

$$
\begin{aligned}
G\left(M_{o}\right) & =\frac{E(F)}{E(H)} \\
& \simeq 1+\frac{1}{2} \sum_{k \in \mathcal{M}} \sum_{l \in \mathcal{M}} \frac{\partial^{2} F}{\partial \theta_{k} \partial \theta_{l}} \operatorname{cov}\left[\theta_{k}, \theta_{l}\right]-\frac{1}{2} \sum_{k \in \mathcal{M}} \sum_{l \in \mathcal{M}} \frac{\partial^{2} H}{\partial \theta_{k} \partial \theta_{l}} \operatorname{cov}\left[\theta_{k}, \theta_{l}\right] \\
& =1+\frac{1}{2} \sum_{k \in \mathcal{M}} \sum_{l \in \mathcal{M}} \frac{\partial^{2}(F-H)}{\partial \theta_{k} \partial \theta_{l}} \operatorname{cov}\left[\theta_{k}, \theta_{l}\right] \\
& =1+\frac{\sigma^{2}}{2} \sum_{k=1}^{M} \frac{\partial^{2}(F-H)}{\partial \theta_{k}^{2}}+r \sigma^{2} \sum_{k=1}^{M} \sum_{l=k+1}^{M} \frac{\partial^{2}(F-H)}{\partial \theta_{k} \partial \theta_{l}}
\end{aligned}
$$

One can compute

$$
\Gamma\left(M_{o}\right) \equiv \frac{1}{2} \sum_{k=1}^{M} \frac{\partial^{2}(F-H)}{\partial \theta_{k}^{2}}=-\frac{M_{o}-1}{M_{o}} \frac{(\varepsilon-1)(1-\rho) \rho}{\varepsilon^{2} \delta^{2}}
$$

which is negative. Similarly, one can also compute the sum $\sum_{k=1}^{M} \sum_{l=k+1}^{M} \frac{\partial^{2}(F-H)}{\partial \theta_{k} \partial \theta_{l}}$, which turns out to be equal to $-\Gamma\left(M_{o}\right)$. Therefore,

$$
G\left(M_{o}\right) \simeq 1-\sigma^{2}(1-r) \Gamma\left(M_{o}\right)<1 .
$$




\section{Derivation of expressions (12) and (13)}

Under small risk, we use Taylor approximations around $\theta_{j}=1$ and the fact that $E \theta_{j}=$

1. Hence, $E \theta_{j}^{1 / \varepsilon} \simeq 1+\frac{1}{\varepsilon} E\left(\theta_{j}-1\right)-\frac{\varepsilon-1}{2 \varepsilon^{2}} E\left(\theta_{j}-1\right)^{2}=1-\frac{\varepsilon-1}{2 \varepsilon^{2}} \operatorname{var}\left(\theta_{j}\right)$. Note then that $F_{j}\left(\mathcal{M}_{I} \backslash \mathcal{M}_{I}^{\prime}, \mathcal{M}_{o}\right)$ can be expressed in terms of $w / w_{0}$ where $w_{0}$ is the wage $w$ under $\theta_{j}=1$ for all $j$. Note that $w_{0}$ is a function of $\mathcal{M}_{I} \backslash \mathcal{M}_{I}^{\prime}$ and $\mathcal{M}_{o}$. Then $E\left(w / w_{0}\right)^{\alpha} \simeq 1$ $+(\alpha-1) \alpha \operatorname{var}\left(w / w_{0}\right) / 2$. Also, using a Taylor approximation around $\theta_{j}=1$ and $w=w_{0}$, we get

$$
\begin{aligned}
E\left[\theta_{j}^{\frac{\rho}{\delta \varepsilon}}\left(w / w_{0}\right)^{-\left(\frac{\rho}{\delta}-1\right)}\right] & \simeq 1-\rho \frac{\varepsilon-1}{\delta^{2} \varepsilon^{2}} \operatorname{cov}\left(\theta_{j}, w / w_{0}\right) \\
& +\frac{(1-\rho) \rho(\varepsilon-1)}{2 \delta^{2} \varepsilon^{2}} \operatorname{var}\left(\theta_{j}\right) \\
& +\rho \frac{\varepsilon-1}{2 \delta^{2} \varepsilon} \operatorname{var}\left(w / w_{0}\right)
\end{aligned}
$$

Using, the Taylor approximation $(1+x)^{y} \simeq 1+x y$, we get

$$
\begin{aligned}
F_{j}\left(\mathcal{M}_{I}, \mathcal{M}_{o}\right) & \simeq 1-\frac{\rho}{2} \frac{\varepsilon-1}{\delta^{2} \varepsilon^{3}} \operatorname{var}\left(\theta_{j}\right)-\frac{1}{2}(\varepsilon-1) \frac{\alpha \varepsilon \delta+\varepsilon-1}{\delta^{2} \varepsilon^{2}} \operatorname{var}\left(w / w_{0}\right) \\
& +\rho \frac{\varepsilon-1}{\delta^{2} \varepsilon^{2}} \operatorname{cov}\left(\theta_{j}, w / w_{0}\right)
\end{aligned}
$$

Therefore, $F_{j}<1$ iff

$$
2 \operatorname{cov}\left(\theta_{j}, w / w_{0}\right)<\frac{1}{\varepsilon} \operatorname{var}\left(\theta_{j}\right)+\varepsilon\left[1+(\alpha-1) \frac{\delta}{\rho}\right] \operatorname{var}\left(w / w_{0}\right)
$$

which is the result in the text.

Suppose now that $M_{o}=0$. So that $w / w_{0}=\Psi_{I-I^{\prime}}^{1 / \varepsilon}$ where $\Psi_{I-I^{\prime}} \equiv\left[\left(1 /\left(M_{I}-M_{I}^{\prime}\right)\right) \sum_{j \in M_{I} \backslash M_{I}^{\prime}} \theta_{j}^{\frac{\rho}{\delta}}\right]^{\frac{\delta \varepsilon}{\rho}}$. Using Taylor approximation for $\theta_{j}$ around 1 , we get $\Psi_{I}^{1 / \varepsilon} \simeq 1+\sum_{k \in \mathcal{M}_{I} \backslash \mathcal{M}_{I}^{\prime}}\left[\partial \Psi_{I-I^{\prime}}^{1 / \varepsilon} / \partial \theta_{k}\right]_{\theta=(1, \ldots, 1)}$ $\left(\theta_{k}-1\right)=1+\frac{1}{\left(M_{I}-M_{I}^{\prime}\right) \varepsilon} \sum_{k \in \mathcal{M}_{I} \backslash \mathcal{M}_{I}^{\prime}}\left(\theta_{k}-1\right)$. So,

$$
\begin{aligned}
\operatorname{var}\left(w / w_{0}\right) & =\operatorname{var}\left(\Psi_{I}^{1 / \varepsilon}\right) \simeq \frac{1}{\varepsilon^{2}\left(M_{I}-M_{I}^{\prime}\right)^{2}} \sum_{k \in \mathcal{M}_{I} \backslash \mathcal{M}_{I}^{\prime}} \operatorname{var}\left(\theta_{k}\right) \\
\operatorname{cov}\left(\theta_{j}, w / w_{0}\right) & =\operatorname{cov}\left(\theta_{j}, \Psi_{I}^{1 / \varepsilon}\right) \simeq \frac{1}{\varepsilon\left(M_{I}-M_{I}^{\prime}\right)} \sum_{k \in \mathcal{M}_{I} \backslash \mathcal{M}_{I}^{\prime}} \operatorname{cov}\left(\theta_{j}, \theta_{k}\right)
\end{aligned}
$$


Hence the previous condition becomes

$$
\frac{2}{M_{I}-M_{I}^{\prime}} \sum_{k \in \mathcal{M}_{I} \backslash \mathcal{M}_{I}^{\prime}} \operatorname{cov}\left(\theta_{j}, \theta_{k}\right)<\operatorname{var}\left(\theta_{j}\right)+\frac{1+(\alpha-1) \frac{\delta}{\rho}}{\left(M_{I}-M_{I}^{\prime}\right)^{2}} \sum_{k \in \mathcal{M}_{I} \backslash \mathcal{M}_{I}^{\prime}} \operatorname{var}\left(\theta_{k}\right)
$$

Letting $m_{I}=\frac{1}{M_{I}-M_{I}^{\prime}} \sum_{k \in \mathcal{M}_{I} \backslash \mathcal{M}_{I}^{\prime}} \theta_{k}$, we get the following simple equivalence:

$$
F_{j}\left(M_{I}, 0\right)<1 \Longleftrightarrow 2 \operatorname{cov}\left(\theta_{j}, m_{I}\right)<\operatorname{var}\left(\theta_{j}\right)+\left[1+(\alpha-1) \frac{\delta}{\rho}\right] \operatorname{var}\left(m_{I}\right)
$$




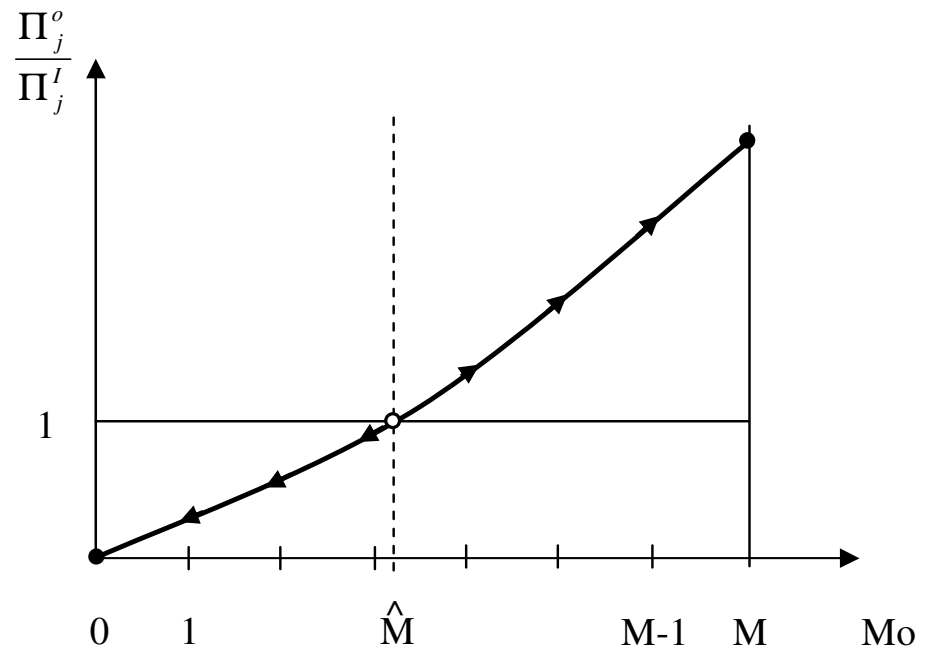

Figure 1: Incentives to Outsource under Certainty 


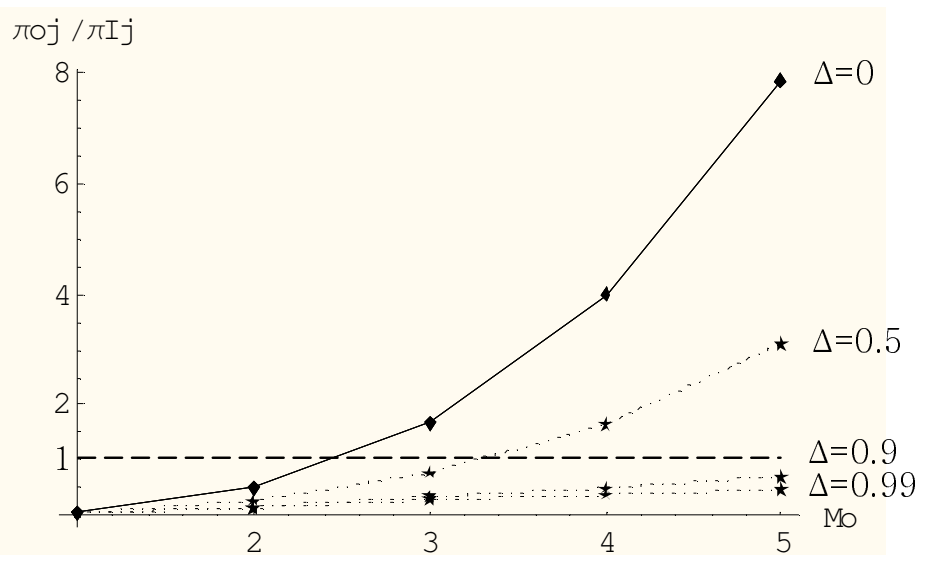

Figure 2: Incentives to Outsource under Uncertainty 